\title{
Dependência espacial da resistência do solo à penetração e do teor de água do solo sob cultivo contínuo de cana-de-açúcar
}

\author{
Spatial variability of soil penetration resistance and soil moisture at different periods of sampling under \\ sugarcane crop
}

\author{
Zigomar Menezes de Souza ${ }^{1}$ Milton César Costa Campos $^{2}$ Ítalo Hebert Lucena Cavalcante ${ }^{3}$ \\ José Marques Júnior ${ }^{2}$ Luiz Gilberto Cesarin ${ }^{4}$ Sandro Rogério de Souza $^{4}$
}

\section{RESUMO}

O cultivo intensivo dos solos e a utilização de máquinas e equipamentos pesados promovem a compactação do solo. A resistência do solo à penetração é uma medida que detecta esta compactação, contudo ela é fortemente influenciada pelo teor de água no solo. O objetivo deste trabalho foi avaliar o efeito do teor de água no solo na variabilidade espacial da resistência do solo à penetração em um Latossolo Vermelho distrófico. Uma área de lha cultivada há 40 anos com cana-de-açúcar foi amostrada nos pontos de cruzamento de uma malha, com intervalos regulares de $10 \mathrm{~m}$, perfazendo um total de 100 pontos. As amostras de solo foram coletadas nas profundidades de 0,00-0,15m, 0,15-0,30m e 0,30-0,45m, 24 e 72 horas após uma chuva de $38 \mathrm{~mm}$. Resultados de resistência do solo à penetração indicaram um estado alto de compactação nas duas épocas de amostragem. O teor de água no solo afetou consideravelmente a variabilidade espacial da resistência do solo à penetração e quanto maior o teor de água menor foi a dependência espacial. A malha de amostragem deve ser mais adensada em relação à utilizada neste estudo quando o teor de água no solo for superior ao observado 72 horas após a chuva, a fim de se avaliar a variabilidade espacial para a resistência do solo à penetração.

Palavras-chave: geoestatística, atributos físicos, latossolos.

\section{ABSTRACT}

The intensive cultivation of soil and the use of machines and equipment promote soil compaction. Soil penetration resistance is a measure that detects this compaction, nevertheless soil moisture influences hardly on soil penetration resistance. The objective of this work was to evaluate the effect of soil moisture on the spatial variability of soil penetration

\begin{abstract}
resistance of an Oxisol. An area cultivated for 40 years with sugarcane was sampled in the crossing points of a regular grid, with $10 \mathrm{~m}$ intervals, comprising 100 points. Soil samples were collected at $0.00-0.15 \mathrm{~m}, 0.15-0.30 \mathrm{~m}$ and $0.30-0.45 \mathrm{~m}$ depths, 24 and 72 hours after a $38 \mathrm{~mm}$ precipitation. Soil penetration resistance values indicated that compaction was high at the two sampling periods. Soil moisture influenced the spatial variability of soil penetration resistance and a smaller spatial dependence was related to higher soil moistures. The grid used for the evaluation of soil penetration resistance variability must be closer than the one used for this study when the soil moisture is higher than the moisture observed 72 hours after the precipitation.
\end{abstract}

Key words: geostatistics, physical attributes, oxisol.

\section{INTRODUÇÃO}

O cultivo intensivo dos solos e a utilização de máquinas e equipamentos pesados na cultura da cana-de-açúcar levam à degradação das condições físicas e, principalmente ao incremento da compactação do solo. A resistência do solo à penetração tem sido freqüentemente utilizada como indicador da compactação do solo em sistemas de manejo, por ser um atributo diretamente relacionado ao crescimento das plantas e de fácil e rápida determinação (STOLF et al., 1983; TORMENA\& ROLOFF, 1996 e MERCANTE et al., 2003).

A resistência do solo à penetração é fortemente influenciada pelo teor de água, textura,

${ }^{1}$ Faculdade de Ciências Agrárias e Veterinárias (FCAV), Universidade Estadual de São Paulo (UNESP). Via de acesso Prof. Paulo Donato Castellane s/n, CEP 14870-900 Jaboticabal, SP, Brasil. E-mail:zigomarms@yahoo.com.br.

${ }^{2}$ Departamento de Solos e Adubos, FCAV/UNESP, Jaboticabal, SP, Brasil. E-mail: agramccc@yahoo.com.br.

${ }^{3}$ Departamento de Produção Vegetal, FCAV/UNESP, Jaboticabal, SP, Brasil. E-mail: italohlc@fcav.unesp.br.

${ }^{4}$ Curso de Biologia, Faculdade São Luis, Jaboticabal, SP, Brasil. E-mail:1cesarin@usinasantaadelia.com.br. 
densidade e composição mineralógica do solo (GOMES \& PEÑA, 1996). Os maiores valores de resistência do solo à penetração ocorreram por ocasião dos menores teores de água no solo, tendendo a um decréscimo linear com o aumento do teor de água (ORLANDO et al., 1998).

Em geral, valores de resistência do solo à penetração, considerados críticos ao crescimento radicular, variam de 1,5 a 3,0MPa. Valores em torno de 2,5MPa são considerados baixos, ao passo que valores em torno de 3,5 a $6,5 \mathrm{MPa}$, são considerados como valores capazes de causar problemas para o desenvolvimento radicular de leguminosas e gramíneas (TORRES \& SARAIVA, 1999).

Ao analisar dados de atributos de solo mediante os métodos estatísticos clássicos são ignoradas as conseqüências da heterogeneidade espacial sobre a representatividade dos valores médios de amostras. No entanto, os métodos geoestatísticos (análise de semivariogramas e krigagem) estão sendo utilizados para analisar tanto a dependência espacial como para interpolar atributos de solo através da krigagem (VIEIRA et al., 1983; TRANGMAR et al., 1985; SOUZA et al., 2001; SOUZA et al., 2004). Este procedimento permite determinar se um atributo apresenta ou não estrutura espacial e, uma vez conhecido o modelo da dependência espacial, é possível mapear a área estudada.

Diversos estudos demonstram que a variabilidade da resistência do solo à penetração e o teor de água no solo não ocorrem ao acaso, mas apresentam correlação ou dependência espacial (SOUZA et al., 2001; UTSET \& CID, 2001; ABREU et al., 2003; MERCANTE et al., 2003). Para diferentes condições de teores de água no solo, distintos comportamentos da variabilidade espacial da resistência do solo à penetração foram observados por UTSET \& CID (2001).

Considerando que o teor de água no solo exerce forte influência nos resultados da resistência do solo à penetração, o trabalho foi desenvolvido em um Latossolo Vermelho distrófico cultivado com canade-açúcar por mais de 40 anos, com o objetivo de avaliar o efeito do teor de água no solo na variabilidade espacial da resistência do solo à penetração.

\section{MATERIAL E MÉTODOS}

A área de estudo localiza-se no nordeste do Estado de São Paulo, no município de Jaboticabal, SP. As coordenadas geográficas são $21^{\circ} 22^{\prime}$ de latitude Sul e $48^{\circ} 15^{\prime}$ de longitude Oeste, com altitude média de $600 \mathrm{~m}$. O clima da região, segundo a classificação de Köppen, é do tipo mesotérmico com inverno seco (Cwa). A precipitação pluviométrica anual média é de $1.400 \mathrm{~mm}$ com chuvas concentradas no período de novembro a fevereiro. O relevo é predominantemente suave ondulado com declividades médias variando de 6 a $11 \%$. O solo é classificado como Latossolo Vermelho distrófico, textura argilosa (LVd), desenvolvido sobre um arenito do Grupo Bauru, Formação Adamantina.

A área estudada tem 40,5ha e vem sendo cultivada com cana-de-açúcar há mais de 40 anos e atualmente está submetida à colheita mecanizada (cana crua). Uma malha com intervalos regulares de $10 \mathrm{~m}$, perfazendo um total de 100 pontos georeferenciados em 1ha, foi disposta no topo da área e as amostras foram coletadas nas profundidades de $0,00-0,15 \mathrm{~m}, 0,15$ 0,30m e 0,30-0,45m, em outubro de 2004.

O teor de água no solo foi obtido pelo método gravimétrico em amostras deformadas (EMBRAPA, 1997). Para determinação da resistência do solo à penetração, utilizou-se um penetrômetro de impacto modelo IAA/Planalsucar com ângulo de cone de $30^{\circ}$. A transformação da penetração da haste do aparelho no solo (cm/impacto) em resistência à penetração foi obtida pela fórmula dos "holandeses", segundo STOLF (1991), a seguir:

$$
R=\frac{M g+m g+\left(\frac{M}{M+m} * \frac{M g * h}{x}\right)}{A}
$$

onde $\mathrm{R}$ é a resistência à penetração, $\mathrm{kgf} \mathrm{cm}^{-2}\left(\mathrm{kgf} \mathrm{cm}^{-2}\right.$ * 0,098 = MPa); $\mathrm{M}$ a massa do êmbolo, $4 \mathrm{~kg}(\mathrm{Mg}-$ 4kgf); $\mathrm{m}$ a massa do aparelho sem êmbolo, 3,2kg (mg$3,2 \mathrm{kgf}$ ); $\mathrm{h}$ a altura de queda do êmbolo, $40 \mathrm{~cm}$; $\mathrm{x}$ a penetração da haste do aparelho, cm/impacto, e A a área do cone, $1,29 \mathrm{~cm}^{2}$.

Realizaram- se determinações da resistência do solo à penetração em duas épocas. A primeira foi 24 horas após uma chuva de $38 \mathrm{~mm}$ (Época 1) e a segunda, 72 horas após a mesma chuva (Época 2). Este procedimento permitiu simular diferentes teores de água no solo e relacioná-los com a variabilidade espacial da resistência do solo à penetração.

Os atributos resistência do solo à penetração e teor de água no solo foram analisados através da análise estatística descritiva e de técnicas de geoestatística. A hipótese de normalidade dos dados foi testada pelo teste de Kolmogorov-Smirnov, por meio do programa computacional SAS (SCHLOTZHAVER \& LITTELL, 1997). A dependência espacial foi analisada por meio de ajustes de semivariogramas através do programa $\mathrm{GS}^{+}$, com base 
na pressuposição de estacionariedade da hipótese intrínseca (VIEIRA et al., 1983), a qual é estimada por:

$$
\hat{\gamma}(h)=\frac{1}{2 N(h)} \sum_{i=1}^{N(h)}\left[Z\left(x_{i}\right)-Z\left(x_{i}+h\right)\right]^{2}
$$

onde $\mathrm{N}$ (h) é o número de pares experimentais de observações, $\mathrm{Z}\left(\mathrm{x}_{\mathrm{i}}\right)$ e $\mathrm{Z}\left(\mathrm{x}_{\mathrm{i}}+\mathrm{h}\right)$, separados por uma distância h. O semivariograma estimado é representado pelo gráfico $\hat{\gamma}(h)$ versus h. Do ajuste de um modelo matemático aos valores calculados de são estimados os coeficientes do modelo teórico para o semivariograma (o efeito pepita, $\mathbf{C}_{\mathbf{0}}$; patamar, $\mathbf{C}_{\mathbf{0}}+\mathbf{C}_{\mathbf{1}}$; $\mathrm{o}$ alcance, a). Os modelos de semivariogramas foram o esférico, o exponencial, o linear e o gaussiano (McBRATNEY \& WEBSTER, 1986), sendo ajustados pelo programa de computador $\mathrm{GS}^{+}$(ROBERTSON, 1998). Para analisar o grau da dependência espacial dos atributos em estudo, utilizou-se a classificação de CAMBARDELLA et al. (1994), em que são considerados de dependência espacial forte os semivariogramas que têm um efeito pepita menor ou igual a $25 \%$ do patamar, moderada quando está entre 25 e $75 \%$ e fraca quando for maior que $75 \%$.

No caso de mais de um modelo para o mesmo semivariograma, foi escolhido o de maior valor do coeficiente de correlação obtido pelo método de validação cruzada e o de melhor coeficiente de determinação $\left(\mathrm{R}^{2}\right)$.

\section{RESULTADOS E DISCUSSÃO}

Os valores médios de resistência do solo à penetração na época 1 e na profundidade de $0,00-0,15 \mathrm{~m}$, foram classificados como moderados de acordo com (SOIL SURVEY STAFF, 1993) e nas profundidades de 0,15-0,30m e 0,30-0,45m como alto (Tabela 1 ). Na época 2 , os valores foram classificados como alto em todas as profundidades estudadas. Houve aumento da resistência do solo à penetração da profundidade de 0,00-0,15m para a profundidade de $0,15-0,30 \mathrm{~m}$, passando de 1,99 para $2,93 \mathrm{MPa}$ na época 1 e 2,30 para $3,77 \mathrm{MPa}$ na época 2 , com diminuição da resistência do solo à penetração na profundidade de $0,30-0,45 \mathrm{~m}$, o mesmo comportamento foi verificado nas duas épocas de amostragem estudadas.

Observa-se, na tabela 1, valores altos de resistência do solo à penetração nas duas épocas de amostragem. Embora os teores de água no solo estejam próximo da capacidade de campo (época 1),os valores de resistência à penetração são considerados impeditivos ao desenvolvimento radicular das culturas, resultados semelhantes foram encontrados em latossolo por TORMENA (1998). DEXTER (1987) afirma que a compactação do solo é mais prejudicial em solo seco, e em condições de maior teor de água no solo pode haver crescimento radicular em valores de resistência do solo à penetração superiores a 4,0MPa.

$\mathrm{O}$ teste de normalidade indicou normalidade para teor de água no solo em todas as profundidades e nas duas épocas amostradas e, resistência do solo à penetração nas profundidades de 0,15-0,30m e 0,30$0,45 \mathrm{~m}$ na época 1 (Tabela 1 ). Os valores da média e mediana, para todas as variáveis, estão próximos, mostrando distribuições simétricas, o que pode ser confirmado pelo coeficiente de assimetria próximo de zero.

A variável resistência do solo à penetração apresentou coeficiente de variação (CV) alto de acordo com a classificação proposta por WARRICK \& NIELSEN (1980) em todas profundidades e épocas estudadas (Tabela 1), concordando com os resultados obtidos por SOUZA et al. (2001), UTSET \& CID (2001) e ABREU et al. (2003). Para o teor de água no solo o CV foi baixo em ambas as profundidades para a época $2 \mathrm{e}$ médio em todas as profundidades na época $1 . \mathrm{O} \mathrm{CV}$ para resistência do solo à penetração na época 1 foi maior quando comparado com a época 2 , isto deve-se provavelmente ao maior teor de água no solo na época 1, corroborando com os resultados de UTSET \& CID (2001) que verificaram para condições de solo seco um $\mathrm{CV}$ de $25 \%$, enquanto sob condição de solo úmido, o CV foi de $80 \%$.

A resistência do solo à penetração na época 2 (Tabela 2 e Figura 1), apresentou dependência espacial em todas as profundidades estudadas expressa por meio dos modelos de semivariogramas. Na época 1 a resistência do solo à penetração apresentou distribuição aleatória (efeito pepita puro), provavelmente devido ao alto teor de água no solo. Na época 2, os dados da variável resistência do solo à penetração ajustaram-se ao modelo exponencial na profundidade $0,00-0,15 \mathrm{~m}$ e esférico nas profundidades de 0,15-0,30m e 0,30-0,45m. Para o teor de água no solo avaliados nas duas épocas de amostragem (Tabela $2 \mathrm{e}$ Figura 2), os dados ajustaram-se ao modelo esférico nas profundidades de $0,00-0,15 \mathrm{~m}$ e $0,15-0,30 \mathrm{~m}$ e exponencial na profundidade de $0,30-0,45 \mathrm{~m}$.

Na condição de menor teor de água no solo, os dados apresentaram dependência espacial (Tabela 2 e Figura 2). Resultados semelhantes com aqueles obtidos por UTSET \& CID (2001) os quais avaliando a resistência do solo à penetração, observaram o modelo esférico ajustando-se aos dados sob condição de solo 
Tabela 1 - Estatística descritiva para as variáveis resistência do solo à penetração (MPa) e teor de água no solo $\left(\mathrm{kg}^{\mathrm{kg}} \mathrm{kg}^{-1}\right)$ nas profundidades de $0,00-0,15 \mathrm{~m}, 0,15-0,30 \mathrm{~m}$ e $0,30-0,45 \mathrm{~m}$, em diferentes épocas de amostragem.

\begin{tabular}{|c|c|c|c|c|c|c|}
\hline \multirow{3}{*}{ Estatística } & \multicolumn{4}{|c|}{ Resistência do solo à penetração (MPa) } & \multicolumn{2}{|c|}{ Teor de água no solo $\left(\mathrm{kg} \mathrm{kg}^{-1}\right)$} \\
\hline & \multicolumn{6}{|c|}{ Profundidade (m) } \\
\hline & $0,00-0,15$ & $0,15-0,30$ & $0,30-0,45$ & $0,00-0,15$ & $0,15-0,30$ & $0,30-0,45$ \\
\hline & \multicolumn{6}{|c|}{ Época 1} \\
\hline Média & 1,99 & 2,93 & 2,77 & 0,20 & 0,19 & 0,19 \\
\hline Mediana & 1,92 & 2,89 & 2,76 & 0,19 & 0,20 & 0,19 \\
\hline Mínimo & 1,22 & 1,24 & 1,67 & 0,15 & 0,14 & 0,15 \\
\hline Máximo & 3,65 & 4,15 & 4,05 & 0,22 & 0,22 & 0,21 \\
\hline Assimetria & 0,13 & 0,14 & 0,12 & 0,32 & 0,14 & $-0,03$ \\
\hline Curtose & $-0,70$ & $-0,21$ & 0,89 & 1,42 & $-0,67$ & $-0,64$ \\
\hline${ }^{1} \mathrm{CV}(\%)$ & 38,03 & 37,67 & 36,07 & 16,81 & 15,98 & 15,63 \\
\hline \multirow[t]{2}{*}{${ }^{2} \mathrm{~d}$} & 0,10 & $0,06^{\mathrm{ns}}$ & $0,08^{\mathrm{ns}}$ & $0,07^{\mathrm{ns}}$ & $0,06^{\mathrm{ns}}$ & $0,08^{\mathrm{ns}}$ \\
\hline & \multicolumn{6}{|c|}{ Época 2} \\
\hline Média & 2,30 & 3,77 & 3,60 & 0,15 & 0,15 & 0,15 \\
\hline Mediana & 2,26 & 3,70 & 3,66 & 0,14 & 0,15 & 0,15 \\
\hline Mínimo & 1,07 & 1,45 & 1,65 & 0,14 & 0,14 & 0,13 \\
\hline Máximo & 4,15 & 6,56 & 6,18 & 0,21 & 0,19 & 0,19 \\
\hline Assimetria & 0,39 & 0,42 & $-0,04$ & 0,10 & $-0,18$ & $-0,002$ \\
\hline Curtose & $-0,41$ & 0,31 & 0,24 & $-0,83$ & $-0,24$ & $-0,49$ \\
\hline $\mathrm{CV}(\%)$ & 25,78 & 24,19 & 24,57 & 4,49 & 4,77 & 4,72 \\
\hline d & 0,10 & 0,14 & 0,13 & $0,07^{\text {ns }}$ & $0,05^{\mathrm{ns}}$ & $0,04^{\mathrm{ns}}$ \\
\hline
\end{tabular}

${ }^{1} \mathrm{CV}=$ coeficiente de variação; ${ }^{2} \mathrm{~d}=$ teste de normalidade, ${ }^{\mathrm{ns}}$ não-significativo a $5 \%$ de probabilidade pelo teste Kolmogorov-Smirnov.

Tabela 2 - Estatística descritiva para as variáveis resistência do solo à penetração (MPa) e teor de água no solo (kg kg-1) nas profundidades de $0,00-0,15 \mathrm{~m}, 0,15-0,30 \mathrm{~m}$ e $0,30-0,45 \mathrm{~m}$, em diferentes épocas de amostragem.

\begin{tabular}{|c|c|c|c|c|c|c|}
\hline \multirow{3}{*}{ Estatística } & \multicolumn{3}{|c|}{ Resistência do solo à penetração (MPa) } & \multicolumn{3}{|c|}{ Teor de água no solo $\left(\mathrm{kg} \mathrm{kg}^{-1}\right)$} \\
\hline & \multicolumn{6}{|c|}{ Profundidade (m) } \\
\hline & $0,00-0,15$ & $0,15-0,30$ & $0,30-0,45$ & $0,00-0,15$ & $0,15-0,30$ & $0,30-0,45$ \\
\hline & \multicolumn{6}{|c|}{ Época 1} \\
\hline Modelo & ${ }^{1} \mathrm{EPP}$ & EPP & EPP & Esférico & Esférico & Exponencial \\
\hline Efeito pepita $\left(\mathrm{C}_{0}\right)$ & 0,23 & 2,50 & 0,48 & 1,15 & 0,17 & 0,36 \\
\hline Patamar $\left(\mathrm{C}_{0}+\mathrm{C}_{1}\right)$ & --- & --- & --- & 2,89 & 0,90 & 1,26 \\
\hline Alcance (a) & --- & --- & --- & 34,3 & 20,4 & 33,6 \\
\hline${ }^{2}\left[\mathrm{C}_{0} /\left(\mathrm{C}_{0}+\mathrm{C}_{1}\right)\right] \times 100$ & -- & --- & --- & 40 & 19 & 29 \\
\hline${ }^{3} \mathrm{R}^{2}(\%)$ & --- & --- & --- & 0,92 & 0,83 & 0,80 \\
\hline \multirow[t]{2}{*}{${ }^{4} \mathrm{VC}$} & --- & --- & --- & 0,92 & 0,91 & 0,90 \\
\hline & \multicolumn{6}{|c|}{ Época 2} \\
\hline Modelo & Exponencial & Esférico & Esférico & Esférico & Esférico & Exponencial \\
\hline Efeito pepita $\left(\mathrm{C}_{0}\right)$ & 0,11 & 0,16 & 0,18 & 0,24 & 0,11 & 0,21 \\
\hline Patamar $\left(\mathrm{C}_{0}+\mathrm{C}_{1}\right)$ & 0,38 & 0,84 & 0,68 & 0,47 & 0,51 & 0,73 \\
\hline Alcance (a) & 48,6 & 21,2 & 20,8 & 30,5 & 23,8 & 24,7 \\
\hline$\left[\mathrm{C}_{0} /\left(\mathrm{C}_{0}+\mathrm{C}_{1}\right)\right] \times 100$ & 29 & 19 & 26 & 51 & 22 & 29 \\
\hline $\mathrm{R}^{2}(\%)$ & 0,95 & 0,92 & 0,95 & 0,94 & 0,93 & 0,81 \\
\hline $\mathrm{VC}$ & 0,89 & 0,91 & 0,87 & 0,89 & 0,90 & 0,87 \\
\hline
\end{tabular}

${ }^{1}$ EPP - Efeito Pepita Puro; ${ }^{2}\left[\mathrm{C}_{0} /\left(\mathrm{C}_{0}+\mathrm{C}_{1}\right)\right] \mathrm{x} 100$ - grau de dependência espacial; ${ }^{3} \mathrm{R}^{2}$ - coeficiente de determinação; ${ }^{4} \mathrm{VC}=\mathrm{coeficiente}$ de correlação do teste de validação cruzada. 


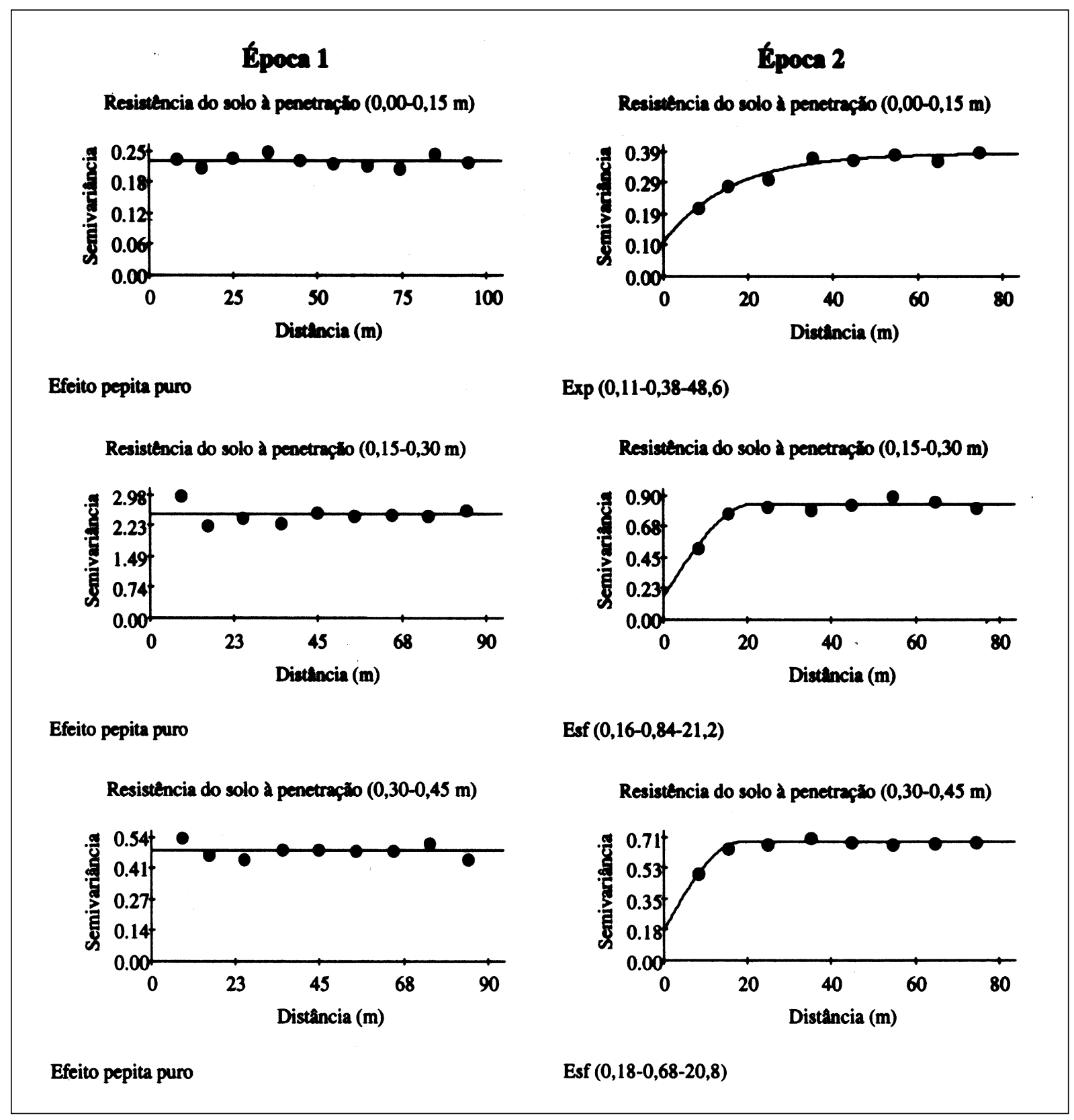

Figura 1 - Semivariogramas da variável resistência do solo à penetração nas profundidades de 0,00-0,15m, 0,15-0,30m e 0,30-0,45m, em diferentes épocas de amostragem. Esf e Exp $\left(\mathrm{C}_{0} ; \mathrm{C}_{0}+\mathrm{C}_{1} ;\right.$ a) é o modelo esférico e exponencial ajustado, $\mathrm{C}_{\mathrm{o}}=$ efeito pepita; $\mathrm{C}_{0}+\mathrm{C}_{1}=$ patamar; $\mathrm{a}=$ alcance.

seco e um efeito pepita puro em condições de solo úmido. Os modelos esférico e exponencial que se ajustaram aos dados deste estudo concordam com os resultados de várias pesquisas que indicam estes modelos como os de maior ocorrência para atributos do solo (SOUZA et al., 1997; SALVIANO et al., 1998; SOUZA et al., 2004).

A variabilidade espacial para resistência do solo à penetração, na época 1 , é muito grande, ou seja, o esquema amostral de $10 \mathrm{~m}$ entre pontos não foi suficiente para captar a dependência espacial para esta variável (Figura 1). Portanto, recomenda-se uma malha mais adensada que a utilizada neste estudo para avaliar a variabilidade espacial da resistência do solo à penetração, quando o teor de água no solo estiver próximo ou acima da capacidade de campo.

O efeito pepita é um parâmetro importante do semivariograma e indica uma variabilidade não

Ciência Rural, v.36, n.1, jan-fev, 2006. 


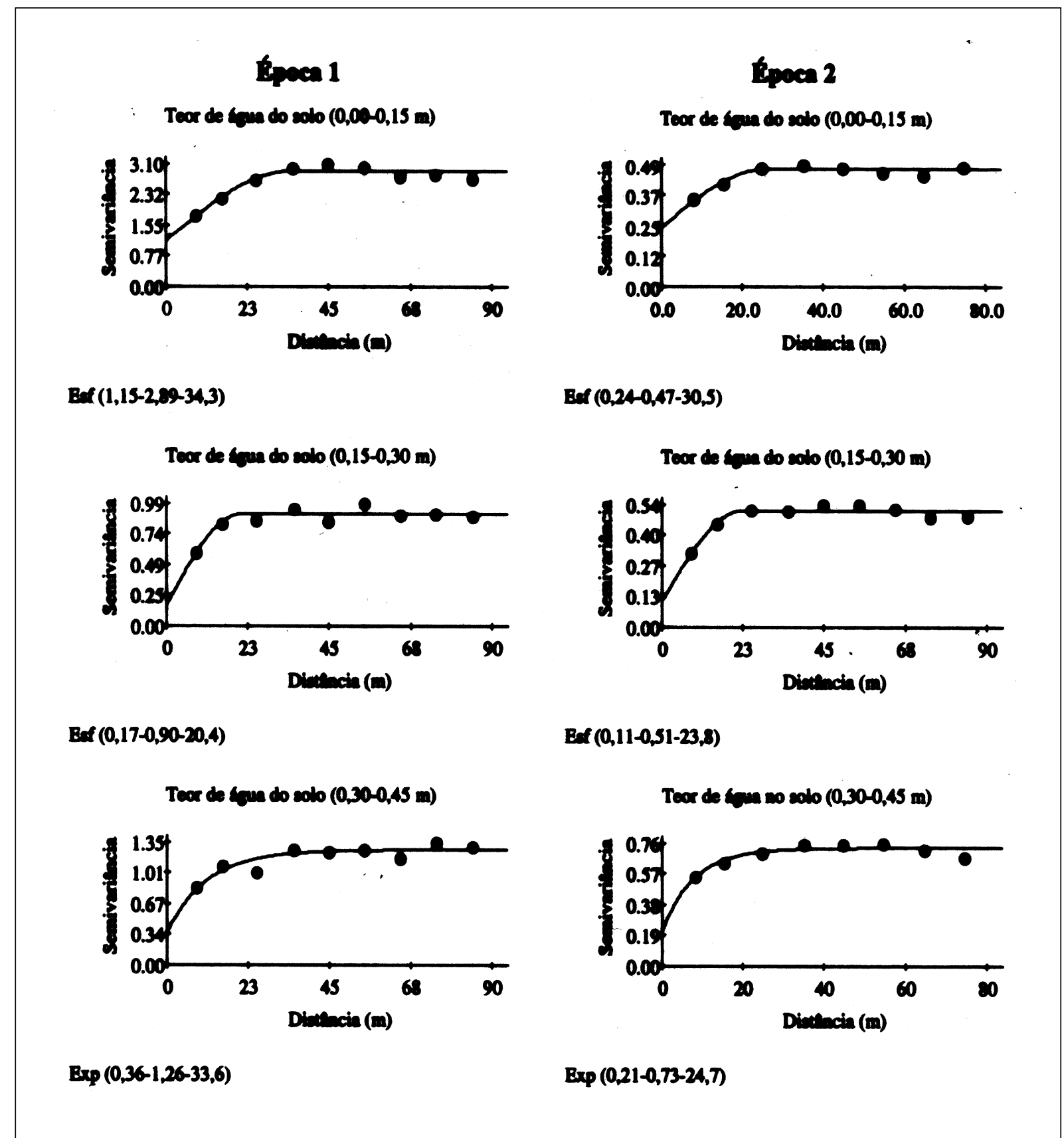

Figura 2 - Semivariogramas da variável teor de água no solo nas profundidades de 0,00-0,15m, 0,15-0,30m e 0,30-0,45m, em diferentes épocas de amostragem. Esf e $\operatorname{Exp}\left(\mathrm{C}_{0} ; \mathrm{C}_{0}+\mathrm{C}_{1} ;\right.$ a) é o modelo esférico e exponencial ajustado, $\mathrm{C}_{\mathrm{o}}=$ efeito pepita; $\mathrm{C}_{0}+\mathrm{C}_{1}=$ patamar; $\mathrm{a}=$ alcance.

explicada considerando a distância de amostragem utilizada (McBRATNEY \& WEBSTER, 1986). Esse parâmetro pode ser expresso como percentagem do patamar, e tem por objetivo facilitar a comparação do grau de dependência espacial das variáveis em estudo (TRANGMAR et al., 1985). A análise da relação $\mathrm{C}_{0} /$ $\left(\mathrm{C}_{0}+\mathrm{C}_{1}\right)$ mostrou que as variáveis resistência do solo à penetração e teor de água no solo apresentaram dependência espacial forte na profundidade de 0,15 -
$0,30 \mathrm{~m}$ e moderada nas profundidades de $0,00-0,15 \mathrm{~m} \mathrm{e}$ 0,30-0,45m nas épocas amostradas (Figuras 1 e 2).

$\mathrm{O}$ alcance (a) indica a distância limite entre pontos correlacionados entre si. Pontos coletados com distância maiores que o alcance são independentes e, para sua análise, pode-se utilizar a estatística clássica (VIEIRA, 2000). As variáveis em estudo apresentaram alcances da ordem de 48,6m para resistência do solo à penetração na profundidade de $0,00-0,15 \mathrm{~m}$ e época $2 \mathrm{e}$

Ciência Rural, v.36, n.1, jan-fev, 2006. 
20,4m para teor de água no solo na profundidade de $0,15-0,30 \mathrm{~m}$ e época 1 . Observaram-se duas classes de valores para o alcance, na profundidade de $0,00-0,15 \mathrm{~m}$ o alcance variou de 30 a $50 \mathrm{~m}$ e nas profundidades de $0,15-0,30 \mathrm{me} 0,30-0,45 \mathrm{~m}$ variou de $19 \mathrm{a} 30 \mathrm{~m}$ em ambas as épocas de estudo, respectivamente (Figuras 1 e 2). MERCANTE et al. (2003) estudaram a variabilidade espacial e temporal da resistência do solo à penetração em áreas com e sem manejo químico localizado em latossolo, e constataram valores de alcances variando de 60 a 80m para uma área de 1 ha, sendo que os maiores alcances foram observados nas áreas com manejo químico localizado e resultados similares a este trabalho nas áreas sem manejo químico localizado.

\section{CONCLUSÕES}

O teor de água no solo afeta a variabilidade espacial da resistência do solo à penetração e no maior teor de água no solo, houve uma menor dependência espacial 24 horas após uma chuva de $38 \mathrm{~mm}$.

A malha de amostragem deve ser mais adensada em relação à utilizada neste estudo quando o teor de água no solo for superior ao observado 72 horas após a chuva, a fim de se avaliar a variabilidade espacial para a resistência do solo à penetração.

\section{AGRADECIMENTOS}

À Fundação de Amparo à Pesquisa do Estado de São Paulo (FAPESP), pela concessão de bolsa de pesquisa a Souza.

\section{REFERÊNCIAS}

ABREU, S.L. et al. Variabilidade espacial de propriedades físicohídricas do solo, da produtividade e da qualidade de grãos de trigo em Argissolo Franco Arenoso sob plantio direto. Ciência Rural, Santa Maria, v.33, n.2, p.275-282, 2003.

CAMBARDELLA, C.A. et al. Field scale variability of soil properties in Central Iowa soils. Soil Science Society of America Journal, Madison, v.58, n.5, p.1501-1511, 1994.

DEXTER, A.R. Mechanics of root growth. Plant and Soil, Dordrecht, v.98, n.3, p.303-312, 1987.

EMPRESA BRASILEIRA DE PESQUISA AGROPECUÁRIA EMBRAPA. Manual de métodos de análise de solo. 2.ed. Rio de Janeiro: Ministério da Agricultura e do Abastecimento, 1997. 212p.

GOMES, A.; PEÑA, Y.A. Caracterização da compactação através do uso do penetrômetro. Lavoura Arrozeira, Porto Alegre, v.49, n.1, p.18-20, 1996.

McBRATNEY, A.B.; WEBSTER, R. Choosing functions for semi-variograms of soil properties and fitting them to sampling estimates. Journal of Soil Science, Oxford, v.37, n.4, p.617$639,1986$.

MERCANTE, E. et al. Variabilidade especial e temporal da resistência mecânica do solo à penetração em áreas com e sem manejo químico localizado. Revista Brasileira de Ciência do Solo, Viçosa, v.27, n.6, p.1149-1159, 2003.
ORLANDO, R.C. et al. Análise de variabilidade do índice de cone para diferentes níveis de teor de água do solo, Poços de Caldas, MG, 1998. In: CONGRESSO BRASILEIRO DE ENGENHARIA AGRÍCOLA, 27., 1998, Poços de Caldas, MG. Anais... Lavras: Sociedade Brasileira de Engenharia Agrícola, 1998. V.3, p.268-270.

ROBERTSON, G.P. GS ${ }^{+}$geostatistics for the environmental sciences: GS ${ }^{+}$user's guide. Plainwell: Gamma Design Software, 1998. 152p.

SALVIANO, A.A.C. et al. Variabilidade espacial de atributos de solo e de Crotalaria juncea $(L)$ em área severamente erodida. Revista Brasileira de Ciência do Solo, Viçosa, v.22, n.1, p.115-122, 1998.

SCHLOTZHAVER, S.D.; LITTELL, R.C. SAS: System for elementary statistical analysis. 2.ed. Cary, SAS, 1997. 905p.

SOIL SURVEY STAFF. Soil survey manual. Washington: USDA-SCS. U.S. Gov. Print. Office, 1993. 437p. (Handbook, 18).

SOUZA, L.S. et al. Variabilidade de propriedades físicas e químicas do solo em um pomar cítrico. Revista Brasileira de Ciência do Solo, Campinas, v.21, n.3, p.367-372, 1997.

SOUZA, Z.M. et al. Variabilidade espacial de atributos físicos em um Latossolo Vermelho Distrófico sob semeadura direta em Selvíria (MS). Revista Brasileira de Ciência do Solo, Viçosa, v.25, n.3, p.699-707, 2001.

SOUZA, Z.M. et al. Variabilidade espacial da estabilidade de agregados e matéria orgânica em solos de relevos diferentes. Pesquisa Agropecuária Brasileira, v.39, p.491-499, 2004.

STOLF, R. et al. Recomendação para uso do penetrômetro de impacto, modelo IAA/Planalsucar - Stolf. São Paulo: MIC/IAA/PNMCA - Planalsucar, 1983. 8p. (Série Penetrômetro de Impacto - Boletim, 1)

STOLF, R. Teoria e teste experimental de fórmulas de transformação dos dados de penetrômetro de impacto em resistência do solo. Revista Brasileira de Ciência do Solo, Campinas, v.15, n.3, p.229-235, 1991.

TORMENA, C.A.; ROLOFF, G. Dinâmica da resistência à penetração de um solo sob plantio direto. Revista Brasileira de Ciência do Solo, v.20, p.333-339, 1996.

TORMENA, C.A. Caracterização e avaliação do intervalo hídrico ótimo de um Latossolo Roxo. 1998. 106f. Tese (Doutorado em Solos e Nutrição de Plantas) Escola Superior de Agricultura Luiz de Queiroz, Universidade de São Paulo.

TORRES, E.; SARAIVA, O.F. Camadas de impedimento do solo em sistemas agrícolas com a soja. Londrina: Empresa Solo em sistemas agrícolas com a soja. Londrina: Empresa Técnica, 23).

TRANGMAR, B.B. et al. Application of geostatistics to spatial studies of soil properties. Advances in Agronomy, New York, v.38, n.1, p.45-93, 1985.

UTSET, A.; CID, G. Soil penetrometer resistance spatial variability in a ferralsol at several soil moisture conditions. Soil \& Tillage Research, Amsterdam, v.61, n.3-4, p.193202, 2001 .

VIEIRA, S.R. et al. Geostatistical theory and application to variability of some agronomical properties. Hilgardia, Berkeley, v.51, n.1, p.1-75, 1983.

VIEIRA, S.R. Geoestatística em estudos de variabilidade espacial do solo. In: NOVAIS, R.F. et al. (Eds). Tópicos em ciência do solo. Viçosa: Sociedade Brasileira de Ciência do Solo, 2000. v.1, p.1-53.

WARRICK, A.W.; NIELSEN, D.R. Spatial variability of soil physical properties in the field. In: HILLEL, D. (Ed.). Applications of soil physics. New York: Academic, 1980. Cap.2, p.319-344.

Ciência Rural, v.36, n.1, jan-fev, 2006. 